\title{
LEVINAS NO OUVIDO DE LYOTARD
}

François-David Sebbah

Université Paris Nanterre

Tradução de Klinger Scoralick

\begin{abstract}
RESUMO: Lyotard leu muito Levinas; foi um dos primeiros a lê-lo rigorosamente e a relação que ele estabeleceu com a obra de Levinas contou de maneira decisiva na elaboração de sua própria obra. Pode-se ficar impressionado com leitura desses textos pela vontade de Lyotard de entender, em um sentido exclusivamente, a Lei em Levinas. E ao ponto de fazer de Levinas, em relação ao que este último marcou explicitamente um desacordo, um "pensador judeu". Pode-se assinalar também que, consagrando um texto ao "rosto", Lyotard não menciona uma palavra de Levinas, que ele lê, aliás, com tanta precisão. No "ouvido" de Lyotard, Levinas é só um "ouvido" convocado, obrigado. E tudo se passa como se isso implicasse colocar de lado o "olho" levinasiano. "Colocar de lado" (e será necessário precisar esse gesto) o olho - ou seja, em um sentido fenomenológico como tal; desviando-se da inscrição sensível; da "encarnação", tanto no sentido fenomenológico quanto no sentido cristão. O "Levinas" de Lyotard não está nem do lado do "rosto" nem do lado do "amor". Certamente, a questão da relação ao fenomenológico de um lado e a relação ao cristianismo de outro sobrepõem-se, sem no entanto coincidir de qualquer maneira que seja. Façamos a hipótese de que essa leitura "radicalizada" e, em um sentido, mutilante do pensamento levinasiano, também esclarecedora, permite entender alguma coisa dos desafios desse pensamento que não se entenderia de outro modo.
\end{abstract}

Palavras-chave: Levinas, Lyotard, Fenomenologia, Ética.

RÉSUMÉ : Lyotard a beaucoup lu Levinas; il a été l'un des premiers à le lire rigoureusement et le rapport qu'il a noué avec l'œuvre de Levinas a compté de manière décisive dans l'élaboration de son œuvre propre. On peut être frappé, à la lecture de ces textes, par la volonté de Lyotard d'entendre en un sens exclusivement la Loi dans Levinas. Et ce au point de faire de Levinas, ce par rapport à quoi ce dernier marqua explicitement un désaccord, un "penseur juif". On peut signaler aussi que, consacrant un texte au "visage", Lyotard ne dit pas un mot de Levinas qu'il lit par ailleurs si précisément et tant. Dans 1' "oreille" de Lyotard, Levinas n'est qu'"oreille" convoquée, obligée. Et tout se passe comme si cela impliquait de mettre de côté 1'“œil" lévinassien. "Mettre de côté" (et il faudra préciser ce geste) l'œil c'est-à-dire en un sens le phénoménologique comme tel; se détourner du coup de 
l'inscription sensible; de 1' "incarnation" tant au sens phénoménologique qu'au sens chrétien. Le "Levinas" de Lyotard n'est ni du côté du "visage" ni du côté de 1'“amour". Bien sûr la question du rapport au phénoménologique d'un côté, et celle du rapport au christianisme de l'autre, se recoupent sans pour autant coïncider en quelque manière que ce soit. Faisons l'hypothèse que cette lecture "radicalisante" et en un sens mutilante de la pensée lévinassienne, est aussi éclairante, permet d'entendre quelque chose des enjeux de cette pensée qu'on n'entendrait pas autrement.

Mots-clés : Levinas, Lyotard, Phénoménologie, Éthique.

Em Discours, figure, Lyotard escreve: "Em sua radicalidade esse retorno à Escritura, entendida como discurso do Outro e como promessa, onde se reúnem pensamento judaico e pensamento cristão demitologizado, renuncia até ao que o olho escuta - que se fecha, que se arranca como o de Édipo. Mestre da ilusão, escravo das ilustrações, o 'mau olho' sempre" ${ }^{1}$. E a frase seguinte se consolida nessa análise por uma referência a Levinas.

Na "nota" Levinas, no coração do Différend, pode-se ler: “(...) o outro em sua privação nem tem nome. Não o chamamos, é ele quem chama" ${ }^{2}$. Algumas páginas mais adiante no decorrer do livro somos surpreendidos por uma fórmula: “(...) não ser mais que o ouvido do não-presentável que o invoca a ele"3.

O que é isso que Lyotard escuta em Levinas? Precisamente, por assim dizer, ele é apreendido pelo ouvido pelo texto levinasiano; um Levinas que, ele próprio, testemunharia ser exclusivamente o ouvido requisitado pelo mandamento.

Pode-se dizer que Lyotard escuta em Levinas o regime disso que em sua língua ele nomeia o "prescritivo", disso que neste último é pura ruptura do descritivo;

\footnotetext{
${ }^{1}$ Klincksieck, Paris, 1971, p. 10.

${ }^{2}$ Ed. de Minuit, Paris, 1983, p. 166.

${ }^{3}$ Ibid., p. 171.
} 
pura ruptura do gênero de discurso suscetível do verdadeiro e do falso, do discurso ligado ao referente. $\mathrm{O}$ prescritivo se constitui como essa própria ruptura, a ruptura da ontologia - do ser e do discurso que lhe convém. Essa ruptura "se entende" e não se "vê", ou, no sentido apontado, entendê-la aqui se opõe então ao compreender, opõe-se à prevalência do modelo do olho em sua conivência com o espaço (o ver como acesso à forma, ao eidos): não ver, não compreender, não ser compelido ao referente, à tentativa de coincidir com o ser. O prescritivo requer o ouvido (deixa-se então de lado o fato da percepção: é claro, há um ser percebido do som); precisamente o ouvido, como o que de mim mesmo é requisitado quando abdico de meu poder de ver; o ouvido que não escuta (no sentido do compreender), mas justamente como a modalidade da recepção da obrigação: interpelado e já agindo segundo a interpelação, sem que nada como um eu seja polo de iniciativa e nem mesmo um polo de centração de uma experiência, seja sobre o caminho desta requisição-ação.

Já no ano de 1970, em "Oedipe Juif", Lyotard citando Bultmann escrevia: "na ética hebraica a representação está proibida, o olho se fecha, o ouvido se abre para escutar a palavra do pai. (...) O modo de perceber Deus, escreve Bultmann, é a audição. A audição é o fato - abolindo toda a distância - de se saber alcançado (...). Assim não se especula, não se faz ontologia como diria Levinas" ". (E é importante observar que, efetivamente, Lyotard tende a colocar em equivalência "ética hebraica" e pensamento levinasiano nesse fechamento do olho).

Se a obrigação obriga é somente enquanto denuncia o "jogo da linguagem da verdade" como sendo apenas jogo possível, e que ela se dispensa dele. Nesse outro "jogo", o da obrigação, está implicado o ouvido ao invés do olho; um agir já sob o golpe de injunção (pode-se reportar à "tentação da tentação", a leitura talmúdica na qual Levinas comenta o "fazer antes de entender" no qual estão engajados os

\footnotetext{
${ }^{4}$ In Dérive à partir de Marx et Freud, UGE 10/18, 1973, pp. 167-188.

${ }^{5}$ Ibid., pp. 174-175.

${ }^{6}$ Quatre Lectures talmudiques, Ed. de Minuit, Paris, 1968, pp. 67-109.
} 
israelitas, comentário que terá sido retido, particularmente, por Lyotard); um agir sem Eu, que é também, e assim, sem Olho (Eye/I, escreve por sua vez R. Rorty). Trata-se de um jogo que se joga fora do ser, fora do mundo. Tal é o mandamento, que sem razão e sem se referir a nenhum elemento da ontologia, comanda na medida que comanda, desde que haja mandamento, na medida que interrompe a ordem do ser e do saber, e, desta forma, pura força performativa, intima-me à pura posição de destinatário. Lyotard inisiste sobre isso: a "sentença ética" é tal que, recebendo-a, por assim dizer, frontal e violentamente, colocado como puro destinatário, essa própria posição implica para mim alguma coisa como um emissor (isso "chama", caso contrário não seria a ética); mas tudo na mesma medida em que esse emissor permanece um lugar vazio, que eu não possa dela constituir a experiência (não identifico o "alguém" que chama), caso contrário não seria a ética: não o "vejo".

Tal é, esquematicamente reintegrado, o "jogo de linguagem" - sempre para falar a língua de Lyotard (ela própria em certa medida proveniente da de Wittgenstein) - que se nomeia "Levinas" segundo Lyotard.

Todo o interesse da leitura lyotardiana é o seguinte: em um sentido, é preciso concordar absolutamente; e, no entanto, em um outro sentido, parece excessivo ao ponto de poder parecer como mutilante. Todo o interesse se situa aí: Lyotard tem absolutamente razão em sublinhar a ausência de concessão, de compromisso ou de comprometimento que constitui o mandamento enquanto tal, como interrupção da ordem do ser, do saber - e partindo de meu ser (interrupção ou suspensão do Eu como conatus) -, isso segundo o próprio Levinas. E, é claro, quando menciona Levinas faz questão de fazer dele um "pensador judeu", não o pensa pela subordinação do pensamento levinasiano à autoridade da Torá; é a exclusividade e a radicalidade desse ouvido, se posso dizer. No ouvido de Lyotard, Levinas é só um ouvido.

Mas essa ausência de comprometimento com a fenomenalidade que se atribui ao olho, reivindicada por Lyotard, tem várias consequências: primeiro, se nada do mandamento se vê então não será suficiente escrever, como o faz Levinas em Totalité et Infini, que o "rosto fala" (e assim me convoca). Seria preciso sustentar que em 
"Levinas" não há "fazer face", que o mandamento só comanda desde o "sem rosto" - se o "rosto", apesar de não se deixar prender em sua forma e no espetáculo da fenomenalidade, mostra-se ainda sobre o modo paradoxal da explosão e do rastro; se o rosto inelutavelmente toca o visível e concerne também o olho. No texto de 1970, "Oedipe juif", Lyotard admite que para Levinas "a Torá é dada na luz de um rosto"7, mas para insistir sobre a invisibilidade ligada ao rosto e terminar por concluir: "em face da Odisseia do olho, que se encerra no sol, a renúncia sem retorno" 8 . Para Lyotard, "Levinas" é exclusivamente o nome do Infinito para além da Odisseia que se fecha em sua totalidade; e a Odisseia é Odisseia do olho - o olho só está do lado da Odisseia. Em verdade, Lyotard não evita o "rosto" em Levinas, mas em toda coerência com sua exigência tende a quebrar a tensão de visível e de invisível que o caracteriza, dissociando o que é em Levinas interrupção da fenomenalidade diretamente sobre a fenomenalidade, como se a evidência do rosto de outrem, já que é preciso bem conceder-lhe um lugar e uma função, fosse o ponto evanescente do fechamento do olho, até mesmo de sua extração, como abertura do ouvido (à injunção do mandamento). A propósito dessa comprovação, em Discours, Figure, Lyotard escreve: "esse padecer é dito bom, compreende o infinito no rosto; o agir do olho seria, ao contrário, a paixão, o desvio" 9 .

Será necessário dizer, de modo mais geral e do mesmo movimento, que para Lyotard a ética não deve ter qualquer relação com a fenomenologia, visto que o "jogo de linguagem" da fenomenologia implica, mesmo sobre um mundo tenso e torturado, uma relação com a experiência, com a experiência que assume e constitui ainda um "eu" (deve-se manter relação com a presença, com o ser, com a experiência, com o ver, com o saber). Em Différend, sempre a propósito de Levinas: "Muito longe de me enriquecer, de dar-me a ocasião de aumentar e de iluminar minha experiência, a chegada do outro me suprime como sujeito de uma

\footnotetext{
${ }^{7}$ Levinas, ibid., p. 103, citado por Lyotard in Dérive à partir de Marx et Freud, op. cit., p. 178.

${ }^{8}$ Ibid., p. 179.

${ }^{9}$ Op. cit., p. 11.
} 
experiência" ${ }^{10}$. E, algumas linhas mais à frente, Lyotard exprime uma inquietude a propósito do texto de Levinas: "será que esse texto não é fenomenológico?" - uma inquietude que soará de maneira surpreendente nos círculos fenomenológicos onde se ouve, tão frequentemente, exprimir a inquietude inversa! "Será que esse texto não é fenomenológico?" - tal é a questão para Lyotard. Seu gesto o conduz precisamente a pensar como testemunho a escritura que seria absolutamente isenta da descrição da experiência, e somente assim estaria à altura da santidade - e não sacrificial, diz ele - (a escritura santa em um sentido muito preciso aqui). O testemunho é, para Lyotard, a modalidade da expressão da ética na medida em que é absolutamente sem ligação com o registro da experiência, que ainda está do lado do ser, do saber. Lyotard exige, assim, não o testemunho de ofuscamento de todo poder (que ainda é um poder, nem que seja apenas poder extenuado da exibição de seu próprio ofuscamento), mas o libertar o testemunho de toda experiência, e mesmo de toda evidência assumível por um "eu", um "eu" que revestiria seus espíritos para narrar. O testemunho como escritura para o outro, sob a lei do outro (é assim que Lyotard quer ler Levinas) é seguramente "confidência de refém", segundo a palavra de Lyotard de sempre ${ }^{11}$. E a "confidência de refém" está bem no coração do texto levinasiano. Mas para Levinas ela não é - confira as páginas sobre o testemunho no capítulo V de Autrement qu'être ou au-delà de l'essence - partilhável da descrição da comprovação do Eu que sente, do "eu" que, no entanto, recebe aliás a si mesmo nessa própria comprovação.

Ao contrário, para Levinas, esse é o lugar do próprio nascimento do Eu que testemunha e se deixa desde então descrever como a própria reviravolta do Infinito (Infinito que se dá pela minha "boca"): não sou nada mais do que a glória do Infinito - subjetividade que nasce como resposta a uma injunção inassumível, entretanto. E é preciso, sem dúvida, acrescentar que segundo Levinas o $\mathrm{Si}$ - a fim de sentir sua

\footnotetext{
${ }^{10}$ Op. cit., p. 167.

${ }^{11}$ Mais exatamente, Lyotard escreve: "O texto de Levinas seria a confidência de um refém", Le Différend, op. cit., p. 167.
} 
própria defecção, o grão de alteridade ou de loucura que o institui - deve no mesmo movimento manter a exigência de centração e de reunião em que também consiste, e que somente pode fazer a comprovação da ferida que o feri, que somente ele pode testemunhar - agora o tecido da apofântica, certamente para o rasgar, mas o agora nesse próprio gesto.

Viu-se que para Lyotard, pelo contrário, o testemunho como "confidência" de refém deve ser absolutamente separado da experiência de um "eu" e mesmo da evidência de um "eu", sob pena de ser perdido.

Para cada um dos dois protagonistas é o outro que cede sobre a radicalidade do testemunho ético, da ética como testemunho: assumir sua amarração irredutível à fenomenologia segundo Levinas; assumir desatá-la absolutamente segundo Lyotard.

Em "Lyotard", "Levinas" será o nome da obrigação como dom de uma ausência, fora do saber, fora do ver, que atinge o ouvido do destinatário suprimido como o eu de uma experiência - e, entretanto, é preciso notá-lo, assim destinatário (ou seja, o inverso do intercambiável e do anônimo). Um "Levinas" - se nomeio aqui "Levinas" um gesto de pensamento e um meio no qual pensar - que exigiria o "sem rosto" e exigiria o "fora da fenomenologia".

Sobre essa primeira série de observações a respeito, poderíamos dizer, do "fenomenológico" como tal, é preciso acrescentar uma segunda série de observações que sobrepõe a primeira sem coincidir exatamente com ela, uma série de observações quanto a essa circunstância ética: a ética nesse "jogo Levinas" não se dá somente como fora do saber, fora do próprio saber da revelação (se esta última é ainda um modo do mostrar); é preciso acrescentar que ela não se inscreve em nada no sensível. Não é amor; não tem nada de um sacrifício para outrem: na "ética segundo Levinas" - como compreende Lyotard - sou refém do Outro em sua santidade, sua separaçãoabstração de todo sensível; e, sobretudo, não sou Eu que amo outrem com um amordesmedida que inverte meu conatus e minha concupiscência, amor-desmedida através do qual me substituo a outrem que sofre, assumindo sobre mim seu sofrimento e o sofrimento que ele impõe, e por onde também me esvazio de mim mesmo em uma 
kénosis sacrificial. O "eu" (se "eu" pode convir) da ética levinasiana no ouvido de Lyotard é refém do mandamento e não amor-sacrifício para outrem (para ele, essas duas características se excluem mutuamente e a segunda anula a primeira).

Mais uma vez, todo o interesse está aí, qual seja, que Lyotard talvez tenha, se posso dizer, ao mesmo tempo completa razão e esteja inteiramente errado.

Efetivamente, deve-se entender em Levinas a radicalidade da injunção ética da seguinte maneira: o "eu" é absolutamente deslocado para fora do ser, e desde então, para fora de seu próprio ser, pelo mandamento que não comanda nada além do que tenha mandamento. Mandamento que precisamente desloca o "eu" até expulsá-lo de seu lugar mesmo de "eu", que o interdita de tomar lugar no ser e entre os seres, abstração que abstrai do ser e me abstrai de meu ser - enucleação segundo a palavra de Levinas. "Eu" - que não é o "eu" de modo algum da ontologia e da gneseologia - sou interditado, deslocado, pelo mandamento que precisamente desfaz todo lugar e todo ser - e nada mais. Acrescentar alguma coisa a isso que acabou de ser descrito seria já trair o traumatismo ético, a ética como traumatismo, envolver de novo o trauma em uma narração do ser. Eis aquilo ao que se agarra Lyotard. E como não lhe dar razão? Como, ao contrário, não lhe dar crédito por ter entendido a ponta mais incisiva daquilo que há para se compreender em Levinas? Como não perceber, também, que é em Autrement qu'être e nos textos pertencentes ao mesmo período que essa ética como enucleação e traumatismo se radicaliza?

Além disso, como não perceber imediatamente sobre esse ponto a fidelidade de Lyotard a algo de Levinas? Sabe-se da reticência que Levinas manifesta frequentemente perante o cristianismo (e sabe-se da ambivalência de Levinas, que em outras de suas proposições, longe de ser reticente, aproxima-se o mais perto possível do cristianismo) - o cristianismo, hegeliano por natureza, conservaria o paganismo que ele supera; comprometeria a radicalidade da transcendência e do mandamento com a imanência do sentimento e da interioridade; tornar-se-ia até mesmo aliado, como reconciliação do Infinito e do Mundo por um Deus feito homem atravessando a morte, a gesta da Totalidade especulativa em detrimento da ética do Infinito. E é exatamente nesses termos que Lyotard se exprime na nota 
"Levinas" de Différend: faz questão de compreender exclusivamente Levinas como "frase ética" interrompendo - e se dispensando de - a frase especulativa (frase especulativa com a qual a fenomenologia, que adere à experiência e à presença, seria já compromisso e o cristianismo, à sua maneira, conviria).

Todavia, os mesmos textos de Levinas, os textos em que o mandamento ético é radicalizado (note Autrement qu'être), se posso dizer, desmentem igualmente Lyotard. Nos mesmos textos encontra-se também a continuação, extenuação da nãoposição do refém em substituição a outrem e amor sacrificial. O que Lyotard não poderia ignorar. Isso implica, portanto, que implicitamente a exclusividade de sua leitura consiste em revirar um momento do dito levinasiano contra um outro momento do dito levinasiano...

Esse não é diretamente o objetivo da presente proposta - não faço portanto mais do que assinalar, sem me deter, na medida em que isso permite oferecer todo seu sentido à interrogação aqui produzida. Sabe-se que uma outra leitura de Levinas foi feita, que por assim dizer pode se mostrar, desse ponto de vista, como o simétrico invertido dessa de Lyotard: uma leitura que do ponto de vista fenomenológico (ponderemos de início) liga, firmemente, a convocação por outrem ao rosto como ele se doa; autodoação do rosto, uma vez que o eu como o entende classicamente a fenomenologia, o eu que "se doa" os objetos, é nessa doação absolutamente destituído. O rosto se doando para além da forma do objeto, para além do "possível" manifestado, desde um sujeito constituinte, o rosto como "fenômeno saturado" por detrás da "não-doação", da abstração do mandamento sem rosto, que somente vem ao ouvido. Chamado e convocação, certamente, mas que só convocam para ofuscar o olho (agora, pois, o olho mais do que nunca, para que possa ser ofuscado). Poderia se falar de uma "sobre-doação": "eu" convocado e ofuscado, colocado no acusativo, destituído de todos seus poderes, mas como no último poder dessa destituição ainda aí, ainda "eu", e de um certo ponto de vista, mais do que nunca - o empenhado. Uma "sobre-fenomenologia" se se quer, para além do objeto e mesmo do ser, mas um sempre mais de doação, em vez de uma exceção de toda fenomenologia, sem 
olho e sem presença, sem nada de doação além de uma doação de ausência; uma "sobre-doação", mais do que uma não-doação como mandamento.

Terá sido reconhecido na breve descrição aqui proposta uma leitura de Levinas tal qual a que propõe exemplarmente J.-L. Marion ${ }^{12}$. Essa leitura - é o segundo ponto relacionado - quer transmitir a ética, para além mesmo da santidade, pelo amor; faz dizer a Levinas que o termo "amor" convém ao que visa ${ }^{13}$. É uma leitura especialmente atenta também à substituição enquanto sofrer por outrem. Exatamente, sem dúvida, o que Lyotard insiste em não entender em Levinas quando pretende torná-lo um "pensador judeu". De maneira programática, poderia se arriscar a seguinte hipótese: simetricamente oposto ao de Lyotard, um tal gesto estaria interessado, sem dúvida, em um diagnóstico similar - que ele tenha, em um sentido, completa razão e esteja totalmente errado - pelas mesmas razões, simetricamente invertidas, em relação às que valem para Lyotard.

Se se centra a reflexão sobre o gesto do pensamento de Levinas é preciso se perguntar, de um lado, por que para este último impõe-se que o mandamento ético não seja, todavia, partilhado conforme um traço nítido de toda relação ao phainestaï, ao aparecer, um aparecer inicialmente perceptível e sensível - a parte de Levinas inaudível para Lyotard - e, por que, inversamente, importará sempre, contudo, ouvir também o que Lyotard percebe em Levinas, a cada vez que uma leitura de Levinas poderia ficar tentada de o esquecer. Ou ainda: 1) Por que e como Levinas pode costurar o mandamento ao fenomenológico sem amenizar sua radicalidade, e o que exige um tal ponto de sutura? 2) Como a ética levinasiana pode compor a radical

\footnotetext{
${ }^{12} \mathrm{Cf}$. em particular, Réduction et donation, Recherches sur Husserl, Heidegger et la phénoménologie, PUF, 1989 e Etant donné, Essai d'une phénoménologie de la donation, PUF, Paris, 1997.

${ }^{13}$ Como na famosa entrevista do Centre Sèvre em 1986 em que, precisamente, sobre essas questões intervieram tanto Lyotard quanto J.-L. Marion. Cf. o "debate geral" do colóquio que the foi consagrado no Centre Sèvre em 1986. Cf. p. 74 ss. em Autrement que savoir, Emmanuel Levinas, Editions Osiris, Paris, 1988. Assinalamos que essas páginas foram retomadas em uma coleção de textos de Lyotard consagrados à, ou marcados pela, recepção de Levinas, intitulada Logique de Levinas, Verdier, 2015. Essa coleção, elaborada e apresentada por Paul Audi, inclui o texto "Logique de Levinas" em versão integral (uma versão parcial tinha sido publicada em francês em 1978), assim como um posfácio, "L'Epaisseur de l'Autre", por Gérald Sfez, que, comentando esse texto, lança uma outra luz que essa aqui proposta sobre a relação entre Lyotard e Levinas.
} 
abstração do mandamento e sua inscrição no mais sensível e no mais concreto como o "arrancar-me o pão da boca para o outro" (esta concretude está, aliás, muito presente no judaísmo em geral)? Por que ela manifesta a perseguição pela vulnerabilidade da concretude do rosto de outrem até um morrer-para-outrem sacrificial? Como pode tratar-se aí não de um ceder a respeito da radicalidade do mandamento, mas, ao contrário, de um aumento de radicalidade? E por que, entretanto, é preciso já fazer protestar a abstração do mandamento desde que se "siga" o trauma ético em sua vertente de inscrição sensível? Pois, pelo que se sabe, os dois gestos contrários, senão contraditórios, coabitam no texto levinasiano: o amor e o sacrifício para outrem, encarnados na carne sensível, vem efetivamente manifestar o mandamento; e, em outros textos, Levinas declara sua reticência com relação ao cristianismo em razão, precisamente, da propensão deste último em preferir a imanência sensível da interioridade, do sentimento - o amor - ao rigor do mandamento; em razão da propensão deste último também em vir a encarnar a abstração radical, correndo o risco, sob seu ponto de vista, de re-confinar no Mundo o que o interrompe. Conforme se é receptivo a um ou a outro desses caminhos, que estabelecem a ocasião de uma bifurcação, encontramo-nos no prolongamento da leitura proposta por Lyotard ou, então, naquela que se pode conduzir desde Marion. Mas em "Levinas" os caminhos não bifurcam, entrelaçam-se em sua própria tensão.

Para esclarecer essa tensão produtiva do gesto levinasiano olhemos por um instante (e sem lhe conceder aqui, seria um outro trabalho, o tratamento requisitado para o ponto de vista do estudo do pensamento de Lyotard), olhemos por um instante, portanto, para isso que Lyotard faz por sua própria conta do olho que vê, ele que o dissocia radicalmente do ouvido exigido pelo mandamento. No fundo, desde Discours, Figure, Lyotard tende precisamente a delimitar o descritivo - o dispositivo no qual se ata o referente e a verdade como adequação ao referente - a fim de ressaltar uma ordem ou uma esfera em que se desdobre uma verdade que não seja a contra-parte do falso: a aléthéia antes da divisão entre verdadeiro e falso, desdobramento, segundo suas descrições, do desejo como força e intensidade. É então, principalmente, questão do olho como pulsão se alimentando da "verdade" 
do quadro, o quadro que não é, certamente, nem verdadeiro nem falso; intensidade de pulsões, de desejos, encontrando outros. Algumas citações de Discours, Figure: "o olho é a força. (...) O quadro não é para ler como dizem os semiólogos de hoje em dia, Klee dizia que é para ruminar. (...) Faz ver que ver é uma dança" ${ }^{14}$. Mais à frente, pode-se ler: a verdade do quadro é tal que, como diz Braque, "não tem contrário".

$\mathrm{E}$, sem dúvida, isso que Lyotard denomina o pagão (a noção é muito complexa, apenas irei tocá-la superficialmente) teria para ele uma parte ligada com esse olho pulsional preso na verdade do desejo. Aqui, Lyotard cede inteiramente seu lugar a um outro olho que aquele da teoria, um outro olho que aquele da teoria do saber e do verdadeiro - um olho que tem parte ligada (seria necessário mostrar como) com uma outra palavra que a palavra filosófica, com a palavra sofística. Lyotard delimita o jogo do ser, do verdadeiro (oposto ao falso), do saber; o jogo jogado pelo filósofo - e, dispensando-se do olho da teoria e do saber, descobre um outro olho - o olho da estética verdadeiramente; vibração e tensão da pulsão continuada do desejo. Desse ponto de vista, Lyotard distingue não apenas dois (como anteriormente quando opunha frase especulativa e frase ética), mas ao menos três jogos diferentes: o do saber, o - pagão - do desejo e o do mandamento (o do "pensador judeu"). E ele se fixa ao "rosto", então é como paisagem carnal que o "vê", como Montagne de Cézanne no olho de Merleau-Ponty - como dependendo do registro do pagão precisamente, sem nada do humano ou do ético, aos antípodas do "rosto" segundo Levinas. Ele o vê com o olho pulsional, aquele da "verdade" do desejo. Fui tocado pela leitura de um texto de Lyotard, "Formule charnelle" ${ }^{15}$, integralmente consagrado ao "rosto" e sem nenhuma referência a Levinas (para um grande leitor de Levinas!). Trata-se de um texto, depois de Merleau-Ponty comentando Cézanne, que explica que no mundo da visão "tudo é rosto", uma vez que o rosto faz ver a visão, já que Montagne nos olha... Mas compreende-se porque para Lyotard o rosto

\footnotetext{
${ }^{14}$ Op. cit., p. 14-15.

15 "Formule charnelle", conferência dada no colóquio "Faire visage" de 1996, pp. 273-283, in Misère de la philosophie, Paris, Galilée, 2000.
} 
é pagão e o mandamento é tão rigoroso que se dispensa do próprio rosto: para Lyotard o pensador do rosto é Merleau-Ponty...

No fundo, tudo se passa como se o espaço do pensamento de Lyotard, seu pressuposto (no melhor sentido do termo) da heterogeneidade radical dos gêneros ou dos jogos, de sua intradutibilidade intrínseca entre eles, liberasse-os absolutamente uns dos outros, mantivesse-os sem contaminação: 1) o mandamento sem inscrição que se doaria ao olho da teoria, sem rosto portanto (o mandamento no ouvido, o sem rosto diante do olho arrancado); 2) o "jogo do saber", do olho teorético, da referência verdadeira ou falsa ao ser em sua autonomia; e 3) no mínimo o "jogo pagão", em que pode sobrevir o rosto, nem verdadeiro nem falso, para um olho que não é teórico, mas de desejo.

Levinas quanto a ele se mantém lado a lado, em uma contaminação possível, ao mesmo tempo necessária (é o motivo do rastro), e à conjurar desde então que a transcendência se perde na imanência, arrisca se apagar. Nos textos em que ele expressa uma desconfiança face ao cristianismo, o que ele teme é a conspiração do cristianismo com o paganismo, é o cristianismo como continuação do paganismo. $\mathrm{O}$ paganismo para ele: fechamento à abstração da transcendência. E, sem dúvida, não é o lugar de desenvolver aqui essa análise, a concretude da imanência, o prazer do beber, do comer, do "ver" (que seria um beber ou um comer), o elemental, que se descreve em Totalité et Infini, não se faz rebaixar sem mais sobre o domínio teórico; sem dúvida, entrevê alguma coisa do olho pulsional do paganismo lyotardiano (nisso que para ele ergue da categoria de "ateísmo") - e de modo algum ele o condena. Todavia, a junção não se faz entre Levinas e Lyotard em um ponto em que ela poderia ter sido feita: a concretude do rosto em sua franqueza (veja Totalité et Infini), não será ela a verdade que não é verdade teórica, que se mantém aquém da divisão entre Verdadeiro e Falso? Essa franqueza não se compromete, por outro lado, necessariamente com o gozo no erotismo? (Arrisco a proposição, seja ela também chocante: o rosto ético levinasiano não flerta necessariamente com o "pagão" no sentido de Lyotard?) 
Para fins de esclarecimento, é preciso fazer aqui um breve comentário concernente às categorias de "pagão", de "judaísmo" e de "cristianismo", que não são as mesmas para Levinas e Lyotard, que não se sobrepõem uma à outra. Para Levinas, o pagão $e$ o saber como totalidade, a imanência do sentimento $e$ a estrutura do saber estão do mesmo lado; além do mais, viu-se que o "cristianismo" é suspeito de uma conspiração com eles. Ambos, ou mesmo os três, estão do lado de um comprometimento ao mesmo tempo necessário, legítimo e à conjurar: necessário e legítimo, uma vez que estamos sobre a borda de cá do Mundo, que a explosão do Mundo somente nos é dada desde a fenomenalidade como o que interrompe esta última, delineia-a e transborda-a; e, no entanto, constantemente à conjurar, uma vez que se trata, nisso mesmo, de compreender um "Deus não contaminado pelo ser". E, no fundo, pode-se bem considerar que Lyotard revela Levinas a ele mesmo, ou a alguma coisa dele mesmo quando evoca o mandamento e a santidade mais do que o rosto em sua concretude sensível, do sacrifício e do amor.

Para Lyotard, o ouvido mantido pelo mandamento, a ética do judaísmo, opõe-se à frase especulativa, e o cristianismo é cúmplice desta última. Mas o "pagão" é algo completamente diferente do especulativo e do cristianismo e seria, por assim dizer, tão comprometido com eles quanto a ética judaica. A partir de então, não obstante as antípodas um do outro - como o mandamento no ouvido e no olho pulsional do desejo - o jogo da ética judaica, o jogo de Levinas e o jogo pagão, descobre-se uma forte proximidade em sua recusa comum em relação ao olho teórico.

Fecho esse parêntese relativo ao esclarecimento das noções para me reorientar aqui sobre o coração de minha proposta. Tudo se passa, portanto, como se, libertando por sua própria conta o pagão em um jogo totalmente outro, Lyotard redobrasse, sobrepujasse o rigor do mandamento em sua leitura de Levinas, até fazer jogar o rigor levinasiano contra o próprio Levinas.

E seria ser fiel a Levinas, ao fazer ressoar a anotação lyotardiana, se ocorresse a Levinas chegar a ser infiel à sua própria reticência; se chegasse a arriscar demasiadamente encarnar a transcendência, demasiadamente o inscrever no Mundo, 
demasiadamente dar ao sentimento, ao amor, ao rosto como "encarnação" (ousemos o termo), à kénosis e ao sacrifício; se chegasse, antes, a atrasar demasiadamente já os desdizeres (segundo a exigência própria de seu pensamento); se chegasse a atrasar demasiadamente, já interromper a imanência concreta pela abstração do mandamento.

Sendo assim, seria, simetricamente, ser infiel a Levinas compreendê-lo exclusivamente desde Lyotard, libertar absolutamente o mandamento de toda ligação com o olho - de toda ligação com cada um dos dois olhos, essa do desejo bem como essa da teoria e do saber; e para o remeter exclusivamente ao ouvido cego que não constitui experiência.

Pois, este é o ponto decisivo que acusa a torção à qual Lyotard submete Levinas: para este último estamos, apesar de tudo, no mundo (conforme a segunda frase da primeira seção de Totalité et Infini) e devemos fazer fenomenologia: é somente desde o fio do fenômeno que sua interrupção se verifica; na ofuscação de um "eu" que é assim mantido em sua própria ofuscação; na experiência desfeita em prova mas, desse modo, mantida... Intermitência levinasiana: fio interrompido e já reatado, uma vez que é somente na ferida infligida que se traça a interrupção. Lá onde Lyotard desata, deixa se desdobrar os fios em uma pura heterogeneidade, em suas desavenças irredutíveis: olho fenomenológico duplicado entre o olho do saber (uma fenomenologia ainda husserliana) e o olho da pulsão (estética em particular); mandamento convocando o ouvido; tantos jogos livres uns dos outros, não contaminados uns pelos outros.

E, sem dúvida, se se puxasse o fio relacionado a esse fio da aposta fenomenológica, o fio daquilo que eu chamaria, de maneira por demais brusca, imprudente e esquemática, o devir cristão da ética levinasiana, seria preciso se perguntar por que a abstração do mandamento ético deve, em um sentido inelutável, exceder-se em amor sacrificial, apesar de que é preciso já desdizer esse excesso (que tende a enrijecer-se em excesso do excesso) pela lembrança de um outro excesso, o do mandamento que rompe toda encarnação. 
No fim deste percurso gostaria de perguntar a Lyotard: por que essa exigência de desconexão, de heterogeneidade radical entre os jogos? Fazendo voltar em sua direção, em retorno, e sob forma de questão sua leitura sobre Levinas, gostaria de perguntar: pode-se, deve-se dispensar a exigência do ponto de sutura entre a fenomenologia e a ética, a cicatriz do fio reatado, o Eu que suporta passivamente sem no entanto ser suprimido? Ou ainda, quid das bordas, das contaminações perigosas talvez - mas também necessárias? - entre os jogos? Quid da ambiguidade e de intermitência entre os jogos? (Lyotard, é verdade, experimentou uma outra via para pensar os limites, a das "nuvens de pensamentos" nas bordas sempre desfocadas, que formam um tecido contínuo onde todo ponto de parada contém algo de arbitrário. Ver Pérégrinations ${ }^{16}$.)

Impossibilidade da leitura exclusivamente lyotardiana de Levinas radicalidade que, deixada a ela mesma, oculta um momento decisivo de exigência levinasiana. Todavia, legitimidade sempre renascente da leitura lyotardiana de Levinas, que é tal como o ceticismo de e em "Levinas", o despertar e o desdizer, assim que esta última se deixe - pois que apesar dela e segundo um risco que ela sabe e que ela mesma tematizou, mas um risco que talvez não se possa não ser corrido assim que esta última, portanto, arrisque se deixar prender na armadilha do Mundo em suas encarnações. Poderia se recomendar tal como um costume de Lyotard na leitura de Levinas: "Lyotard" como um dos nomes possíveis da fase cética, que suspende, interrompe o Dito levinasiano a partir do momento em que este último tende a se fazer excessivamente cristão - e mesmo quando nesse caso a exposição a esse excesso é, em certo sentido, comandada pela própria radicalidade desse pensamento. Intermitência de Levinas em que "Lyotard" será como o Desdizer do momento cristão, o Dizer que o faz explodir; "intermitência", isto é, necessidade da radicalidade de cada um dos dois momentos e, ainda assim, necessidade de jamais hipostasiar uma das duas fases em detrimento da outra, uma vez que é somente no

\footnotetext{
${ }^{16}$ Ed. Galilée, Paris, 1990.
} 
contato de seu outro que cada fase da intermitência consegue não se fixar em caricatura. 